\title{
Health in All Policies: Management Model for the Comprehensive Transformation of the System
}

\section{Mandl Stangl J*}

Stadtbergen Leitershofen, Germany

*Corresponding author: Jorge Mandl Stangl, Stadtbergen Leitershofen, Germany, Email: jorge_mandl@yahoo.com

\section{Review Article \\ Volume 4 Issue 2}

Received Date: March 29, 2021

Published Date: April 22, 2021

DOI: $10.23880 /$ jqhe-16000217

\section{Abstract}

The essay explores the components of the approach health in all policies as a management model based on primary health care and its basic principles for health promotion described in the Ottawa Charter and the Adelaide Declaration: citizen participation and community empowerment, intersectorality, personal skills development, timely technologies and governance processes on social determinants of health. In this sense, we propose the transformation of the health system based on the construction of a comprehensive program for the strengthening of the organization through mechanisms of collaboration between the State and the Society, privileging equity and justice in defense of human rights. The document collects lessons learned from practices on the development and strengthening of "Sistemas Locales de Salud" and the Project "Municipios Hacia la Salud" in Venezuela (1989-2000), as well as experiences in other countries. The proposal is presented as a management model for the design, implementation, and governance of redistributive policies with a perspective of multisectoral strategic plan. We conclude that to be effective and efficient, these initiatives need better processes of political and functional decentralization, strong political and executive leadership, inclusive citizen participation, integrality between health and social goals and objectives, consensual planning between society and governments and; continuous accompaniment, monitoring and evaluation.

Keywords: Health System; Health in All Policies; Venezuela

\section{Introduction}

We see the health system as the result of multiple interactions developed by numerous and diverse actors, through a set of organizations - public and private - that share a series of complex and dynamic values and principles with the aim of improve, maintain or restore health; as well as providing sustained, equitable and supportive solutions to the needs and choices people make around quality-of-life conditions related to the right to their health [1-3].

This definition recognizes that health outcomes and health inequity extend beyond the sector, where the health system is a core part of all social policies and is an indispensable condition for achieving the objectives set at Alma Ata the Ottawa Charter the Strategy for Universal Access to Health and Universal Health Coverage and the Sustainable Health Agenda for the Americas 2018-2030 [4-7].

The theoretical basis of our document raises a broad perspective of the policy known as Health in All Policies [8,9], and is underpinned by lessons learned from national Local Health Systems experiences [10-13] and the Municipalities Towards Health Project integrated initiatives to the process of decentralization, participation and democratization of health in Venezuela that took place between 1989 and 1999 $[14,15]$. The analysis of the successes and gaps in its design and implementation, as well as the experiences of other 
countries, allowed us to move beyond the local scope and propose a management model.

We consider it appropriate to distribute the content of the document in several headings so that all the general guidelines as well as the ideas presented constitute a renewed call for debate and public consultation by various actors. In this sense, we started with a conceptualization of health in all policies as a management tool to improve the quality of healthy public policymaking. Secondly, we develop an effective governance perspective that can ensure institutionalization in the decision-making process; as well as convergence towards this model for the full exercise of shared commitments and the agreement to redefine the roles played by the actors involved in the process, their implementation, the main strategies for their implementation, the legal framework, their financing and monitoring/evaluation that articulate the resulting policy in the short, intermediate and long term. Finally, we present a set of reflections that underpin our proposal to shore up a renewed health and wellness system.

\section{Conceptual Framework}

We conceptualize health in all policies as a management model characterized by the sequence of integrated and sustained responses in all state policies, the product of multispectral and trans disciplinary processes of social mediation in order to ensure that all members of society have fair and equitable opportunities to participate in decisions that facilitate changes in their quality of life and health; through a significant transformation in the forms of interaction between political actors, community groups or networks and institutions, within a common historical-cultural environment, in whose dynamics and interrelationship positive impacts of policy initiatives in all sectors of government while contributing to the achievement of the core objectives in other sectors and policy areas [1620].

This definition creates synergies with practices in Primary Health Care, Health Promotion, Access and Universal Health Coverage. In this sense, some key elements to consider for our proposal [21-25].

- The value of health as a human right for the well-being of all citizens and for economic, social development and the benefits for sustainable development;

- health as a result of a wide range of determinants related to social inequities that require shared responsibility and government-supported political response through partnerships and the genuine commitment of civil society in government decision-making;

- policy-making that may have impacts on the current health of the population and on the health prospects of future generations; with principles of equity, social justice, commitment, solidarity, synergies, and empowerment, particularly with vulnerable populations;

- The developing comprehensive multi-sector strategies across all levels as a path that helps address health determinants to close the inequality gap, improve access and coverage of services;

- The implementation of plans, programmes and projects to improve articulated and linked health and well-being between different actors and institutional/community structures in various territorial areas

- The ability to mobilize sufficient resources of all kinds to identify and open windows of opportunity between levels of government, science, academia, private companies, professional organizations and nongovernmental organizations to achieve co-benefits in the long term and;

- The need to regularly deliberate with citizens to link policy changes with broad social and cultural changes, by democratizing evidence and accountability around health and well-being.

Health in all policies is a management model for the development of political collaboration and not merely a technocratic planning tool since it incorporates an overview of society and the whole government for a healthier society; therefore, its formulation and implementation must be inextricably linked to a political project and an approach of social behavior that itself arouses solidarity, passion and credibility.

According to the World Health Organization [26], there is general policy situations in which the implementation of the model is considered useful: 1) Complex health problems. It refers to population health, equity and health system challenges that require cross-sectoral policy solutions; 2) High-impact government policies on health. It targets proposals from non-health sectors that could have a significant impact on health or health equity; 3) Government priority affecting many sectors. This political situation may arise when the government has a high priority target affecting the health sector but its solution requires proactive engagement with other sectors.

In developing the model to address these problems, we first seek to incorporate health considerations into policies related to diverse sectors, providing information and evidence from a solidly entrenched perspective to new forms of political action in areas beyond health and thus strengthen the link between health and other social policies. Second, ensuring that the development of citizens' health and wellbeing is a shared responsibility of all sectors of society and government as a whole, as a key benefit of society in 
achieving social justice with equity. Third, it is intended to optimize the mechanisms of governance, cross-sectoral management and citizen participation for the significance of the implications on health and well-being; which involves analyzing how policies and interventions are linked to health determinants, risk/protection factors, health outcomes, as well as the distribution of these effects across diverse population groups.

For sustainability, a combination of features emerges as important ingredients. We describe these in the following sections.

\section{Governance}

The concept of governance for health and well-being refers to the structures and processes by which political and social actors carry out exchange, coordination, control and decision-making practices aimed at solving the problems, including reducing health inequities or creating community opportunities in the pursuit of health as an integral part of well-being. This is achieved through joint government and societal approaches, underpinned by commitments of solidarity and shared responsibility to achieve sustainable and healthy development [18,27-29].

In essence, these processes of collective action seek to: 1 ) Create political and executive leadership at all levels - vertical and horizontal - that looks outwards, foster dialogue, support experimentation and innovation; 2) provide a competent environment from the highest levels of government for cultural change in practices and ways of working; 3 ) leverage decision-making structures to develop a clearly articulated and shared vision; 4) drive the implementation of work in sectors, membership structures and increase exposure to collaborative opportunities; 5) promote alignment of policy priorities and facilitate an enabling environment for their development; 6) ensure harmonization in policy-making and efforts not to undermine other priorities and; 7) resolve conflicts of interest in a timely and transparent manner.

In its most general expression, it reflects a change in the balance between the State and civil society, in which the emphasis is placed on active citizenship and ultimately links it to broader discussions around procedures. From this perspective, it can be seen as a more inclusive and cooperative process for solving problems of various complexions, by actors not necessarily of the government.

The health and wellness governance model comprises five styles of interaction whose operability is often hybrid in heterogeneous contexts [30,31].

- Governance through citizen participation. It involves interacting with the population and is nourished by the construction of social capital that expands opportunities for innovations through co-production of knowledge of society; it also creates new coordination mechanisms with government agencies, mayors and other local government actors.

- Governance through collaboration. It is a set of repeated efforts to shape agreements involving all stakeholders in the search for healthy conditions, commitments on health justice and shared resources with criteria of equity and accountability.

- Governance through a mixture of regulation and argumentation: It entails the State taking a role as a supporter of dialogue and negotiating alternatives to solve problems by building consensus to reach shared horizons that prioritize the real and felt needs of the majority of the population.

- Governance through external advisors and expert teams: It involves facilitating processes that require interpretation in the development of the role of government institutions and how the various actors participate in the implementation of public policies.

- Governance by adaptive policies: It applies when political systems are complex, characterized by linear relationships and organizational rigidity between actors; producing uncertainty and unforeseen consequences.

Governance involves the creation of a multi-stakeholder structure - including civil society, entrepreneurs and nongovernmental organizations-, to function as a forum for policy discussion, agenda-making and their assessment of impact on health and health equity; in addition to proposing appropriate solutions and overcoming barriers to their implementation. This structure is formed in several power strata such as: Governing Councils, Intersectoral Cabinets, Secretariats and Cabinet Committees when it comes to central government; at the parliamentary level, various committees are established and; at the bureaucratic/civil service level, they are composed of Interdepartmental Committees and Units [32,33].

The actions to be developed in these structures are: a) The co-production of 'shared' evidence; b) reach a multispectral agreement on the objectives and outcomes of the desired public policies; c) improve synergies between sectors, reduce fragmentation of action and mitigate duplication; d) provide guidelines to be followed in terms of joint policies; (e) the mobilization of appropriate funds; e) the mobilization of timely funds; f) seek or encourage legal or legislative changes to align different sectors; g) support the implementation of the resulting proposals, driving, management and supervision; $h$ ) measure progress in social determinants of health and; i) promote a change in attitudes, culture and the social, political or physical environment. 


\section{Strategies}

When this model is used in non-health sectors of the government, the goal is to build a place to improve the policies or proposals considered from a health perspective. In this sense, the most expeditious way is to develop strategies between government partners and organized communities in which mutual gains can be found between goals and objectives through a simple and clear integration of common actions [34].

The development of strong governmental and nongovernmental partnerships is based on co-design, coproduction and collaboration to achieve partnerships through systematic dialogue and consultation focused on public value and well-being of people in order to building citizenship, consolidated in trust and social cohesion to support change. In addition, in order to reconcile the different interests, it assumes flexibility/adaptability in associations, basing its action on jointly constructed or valued evidence and promoting reflection on the practice in changing contexts [35].

The objectives sought should always aim to develop the maximum health potential; promote health gains for the population as a whole and focus on the social determinants of health inequalities. The goal is to achieve policy coherence to ensure progress towards sustainable development and; ultimately, to identify and implement adjustment mechanisms to achieve contextually relevant purposes [36]. To this end, two key strategies are considered.

\section{Drive Cross-Sectoral Integration}

Intersectorality refers to the integration of various sectors with a view to solving complex social problems whose fundamental characteristic is their multi-causality. It involves collaborative relationships, clearly non-hierarchical and even non-contractual, under the imperative of a holistic view of government; which requires more interactive approaches. It's about having a single institution where the organizational or structural unit of the different sectors converges on the achievement of a shared purpose [37].

Greater integration would occur when there is inclusivity among government sectors in deliberative designs and shared planning, common funding arrangements, participatory evaluation and collective governance structures. These processes should result in changes in other policies, whether in their justification, their content, their funding and their application or legal basis, so that a positive influence is achieved on health or determinants of health and, at the same time, to see if the results described have had an impact on health equity [38,39].
Among the facilitating factors that can give cross-sectoral sustainability, are [39,40]

- The importance of political will and public participation through structures that allow the meeting and adhesion between government sectors, such as: social cabinets, interdepartmental committees, or specific steering committees;

- the capacity of stakeholders and common knowledge of key issues and the actions needed to address them, their ability to work together, as well as the behaviour of actors and cultures in various sectors;

- $\quad$ support mechanisms such as strategic planning, impact analysis and unified prioritization;

- the combination of budgets, whether through integrated budgets from various sectors, tax incentives for crosssectoral collaboration, cross-sector agreements on the financing of the shared strategy, participatory budgeting among others;

- mechanisms for monitoring and evaluating crosssectoral interventions with the help of research institutions or universities;

- Mandates such as laws, regulations, protocols, policies and accountability frameworks.

\section{Social Capital Building}

The construction of social capital helps in the application of health in all policies to the extent that it explicitly supports the importance of the transformative social commitment that the model represents, while recognizing the potential indirect positive health consequences by increasing community capacity to work together to solve collective problems [41].

Four critical elements of this dynamic are considered empowerment, understood as the process of social action that promotes political effectiveness in the participation of people, organizations and communities towards the objectives of achieving improvement in quality of life with social justice, as well as greater control individual and community [42]; 2) compatibility. For the success of the model, a work is required where all those involved act comprehensively, also implies the need to link the different cultures and knowledge in common projects, obtaining shared benefits [43]; 3) optimization of processes through the efficient dissemination of new rules and healthy behaviors within the system, as an objective of social change, particularly in the most vulnerable communities; 4) sustainability, understood as the capacity of programs and projects to join and continue regularly in the community, once external assistance is completed [44]. The critical elements for achieving such sustainability are often part of the socio-political dynamic and structure as the number of people and communities involved in the decision-making process increases; as well as increasing their conceptual wealth and the possibility of 
extending the time provided for their development [45].

In this order of ideas, the construction of social capital for the strengthening of health in all policies, includes four key categories to consider.

- Sense of community. It refers to the creation or strengthening of trust in cooperative relationships between individuals of groups that are similar in the way they define themselves, membership and participation in social life. Solidarity and social responsibility around unmet basic needs are the cardinal principles that facilitate the organization of communities.

- Collective efficiency. It refers to the strategies of building identities, senses and social ties, as well as the collective values that serve as a guide when grouping and allow the collective to perceive part of a common world with the capacity to meet the needs of citizens. They are rules, functions and autonomy of communities through deliberative participation in public discussions in order to enable technical and political decisions that are consolidated through various organized monitoring mechanisms and; are established when society achieves more equitable access to decisions about their rights that impact people's lives.

- Community capacity. It refers to characteristics and qualities that are required to participate in a deliberative and critically reflection manner. They give communities access to networks or groups with power in decisionmaking areas and can give decision makers more understanding and influence at the community level. These include: the concept of social justice to privilege the common good for those most in need, with the same opportunities for the whole of society; pluralism and tolerance as an attitude of recognition of diversity and; the respect that others have to think and have a different opinion.

- Community competition. It refers to characteristics of the actions of responsibility and commitment to the community that are implemented to improve the quality of life of citizens; through which citizen participation, the definition and achievement of objectives, understanding and transparency are channeled to express their needs and share information, manage conflicts and reach consensus in decision-making. These provide the triggers for the formation of the social contract.

The diverse ability to mobilize social capital, to enhance social networks in different groups and social strata; makes that resource necessarily lead us to link social capital with the State. From this point of view, it is necessary to establish appropriate and efficient links between the micro level-social networks - at which social capital mobilization programmes are usually located, and the macro level at which most public policies are facilitated.

The success of this process is based on the development of a very active policy aimed at building strategic alliances in order to develop a group integration characterized by a balance between solidarity; shared responsibility; social justice based on similar opportunities for the development of those most in need; individual, political and civil rights of communities to influence those social determinants of health that strengthen these rights at local level and; ethicalpolitical commitment to their obligations in the exercise of true democracy.

\section{Implementation}

The implementation of the model can be conceived as a multispectral initiative explicitly linked to long-term policies, coordinated by formal governmental structures and non-governmental actors - including the community, private sectors and academics [46]. The implementation of appropriate procedures requires focusing on interactions between all stakeholders trying to reconcile the divergent interests of each of the policy sectors that can influence the social determinants of health and health inequities [47].

For it, important institutional, formal and informal adjustments are needed, whose main feature of which is negotiation to address new and interdependent circumstances: these are described as 'joint government' methods to achieve the coherence of national policies and 'whole of society' in order to build coalitions with various actors [17].

Both processes involve two moments [48]: Firstly, the creation of the Agenda to be agreed upon by the various and many potential sectors. This involves: a) Establishing the need and priorities for health in all policies. This requires an in-depth understanding of feasibility to address problems from a health perspective, including awareness of the power dynamics involved; b) form a framework for action within the context of existing strategic guidelines or as joint action plans; c) identify processes and support structures; d) facilitate participation and engagement and; e) ensure monitoring and evaluation that secure model integration into all initiatives that are likely to have an impact on health and health equity.

Second, resolute capacity must be built through: a) Training professionals in acquiring the necessary knowledge and skills; b) generate institutional capacity; c) organize research capacity as well as teaching and research collaboration between sectors; d) improve the potential for teamwork within and between ministries and; e) strengthen the knowledge of the community. Competencies can be acquired by training methods such as seminars and courses, 
but other methods of disseminating knowledge and skills must be explored, including online approaches.

To address the traditional disconnection in implementation initiatives across the various sectors, a variety of methodological tools are used, primarily, Health Situation analysis -HSA- and Health Impact Analysis - HIA-. In order to make these methods feasible, it is recommended to use actors known as 'policy entrepreneurs' made up of a person or team that mainly act outside their own organization, and in these roles, they act as catalyst agents of change with the capacity to negotiate, advocate, explain, connect, demonstrate and convince participants about the added value of trying something new; creating opportunities to advance the establishment of the agenda, the process and results to advance the transformation of the system, and demonstrating the organizational benefits in connection with the development of integrated policies $[26,49,50]$.

Health Situation Analysis is an iterative process developed by Ministry of Health staff that allows to describe, characterize, measure, analyze and explain the health status and its social determinants that affect the population of a clearly defined geographical space in order to maximize health/wellness benefits, and demonstrate how the improvement of health can contribute to strengthening the results, to develop actions that contribute to its solution [51].

The second mentioned component - Health Impact Analysis - is a multidisciplinary, cross-sectoral and participatory process that systematically combines a number of procedures, methods and tools with which a policy, a program can be judged or a project, in relation to its potential effects - sometimes unrecognized, unexpected, or marginalized - in population health, including the distribution of these events within the same population and the identification of appropriate interventions on the future consequences of an ongoing or proposed action $[52,53]$.

\section{Legislative Aspects}

The legislation raised in the model recognizes the right to health as a prerogative in all state policies. It is an inclusive social pact to ensure the sustainability of concerted actions on the structural determinants of the political and economic environment; that aim to reduce the social gradient of health across the population, improve living conditions and promote healthy practices [54].

Its purpose is to define and implement public actions that allow systematic adoption through state and local governments in order to meet and guarantee the needs and legitimate health aspirations of all stakeholders; make visible the health effects of policies embedded in the national development model; advocate for health, working with those corporations whose goals are shared and; create a motivated and highly skilled workforce that, in its many different roles and sectors, can systematically contribute to improving health for the entire population $[55,56]$.

One of the main features of the legislative framework is that it attributes public health work as a shared responsibility of the health sector together with non-health institutions, whose purpose is aimed at communities so that they have a greater control of your own health. Therefore, municipalities, states and ministries at the central level must involve all sectors for health promotion. This assertion is conssoning with the international regulatory context, widely discussed and approved in the Shanghai Consensus on Healthy Cities [57], in relation to prioritizing policies that generate mutual benefits between health and other policies and involve all relevant actors in alliance-based planning.

To ensure that the structural change proposed in the Act is sustained over time, even when there are changes in leadership and staff - specifically to help communities institutionalize the health model in all policies - should be included legal provisions aimed at operating key strategies, including: Executive orders or directives, Health Resolutions in all health policies and ordinances in all policies [58]. Lessons learned through international experiences [59], point out that these various legislative mandates contribute to

- Get high-level political support.

- Ensuring government collaboration in sectors to prioritize actions.

- Engaging with non-governmental organizations.

- Compromise community actors from vulnerable populations in health promotion.

- Consider strategies for eliminating fragmentation and departmentalization in the sectoral context.

- Help resolve tensions between sectors involved in policies, plans and projects.

- Request regular feedback on the participants' process and adjustment as needed.

- Establish realistic expectations for visible results that are combined.

\section{Economic Considerations}

For such processes to be feasible, the State must address important tax reforms that allow it to reduce reliance on contributory benefits and finance policies, plans and programmes of general scope. In this same framework, it is also necessary to establish mechanisms to define priorities in the allocation of resources, which should be based on criteria of health needs and cost effectiveness of interventions and 
not only on political criteria [60].

The ability of governments to conduct these processes and the bargaining power of the different sectors involved rests on some relevant aspects $[61,62]$ for the future debate on the model: 1) It is important to increase the availability of resources and the proportion of public spending for policies, plans and programmes with direct or indirect impact on the health status of the population. 2) It is not necessarily a question of thinking about budget reallocations but increases in allocations and, consequently, tax collection; in addition, a balanced mix of general tax resources and wage taxes. 3) In addition, they also demand tax reforms that increase the relative weight of taxes with greater redistributive potential in order to finance actions to achieve the greatest health benefits for the vulnerable population. 4) Decentralization is an instrument that can be functional; however, it is not in itself the solution to the problems of efficiency and equity, therefore, the allocation to compensating policies between states and municipalities must be incorporated and, consequently, the role of central governments and their budget in order to make extreme efforts to compensate for the unintended effects of this process. 5) The introduction of results-based budgeting methods can be very useful. Focusing on common sense outcomes - for example, those related to health and poverty reduction - can be important for achieving integrated budgets and common accounting. 6) Appropriately-quality timely information is essential to enable better reallocation of funds to the most effective uses; this requires the identification of the various determinants of the population health statuses and their monitoring. 7) Proper reallocation of budgets and the ongoing redefinition of policies will depend on the necessary assessment of the impacts of ongoing policies involving all sectors.

Similarly, in order to consolidate sustainable financing structures, some practical considerations [63] are necessary: a) There must be an acknowledgement that there is a problem widely recorded and widely understood; b) there must be some sense of agreement on what needs to be done about the problem - that is, a particular approach or strategy; c) should have a foundation of evidence that sets out the benefits that would be gained from resource reallocation; $d$ ) there must be an equity objective to ensure that all actors share a goal worth pursuing; e) should have a holistic view of problem solving: a holistic look and realize that when making changes; f) multiple problems coupled with political determinants of health must be addressed. When focused on these kinds of problems that can be solved well, it can be well financed; g) resources for the health of the population should be repositioned, realigned and refocused, placing the focus of discussions on co-facilities, which strengthens the connection of sectors from a macroeconomic perspective, as well as from the perspective of systems that contribute to human flourishing.

In this order of ideas, the following sustainable sources of health financing are considered in all policies [64-66].

- Direct health-oriented funding across all policies: Alludes to practice by one or more levels of government to establish specific new or existing income funds for a specific purpose. Greater flexibility in funds allocated for cross-sectoral actions can help maximize opportunities for action.

- Joint budget or combined budgets: This is a practice in which two or more sectors share their resources to solve a problem; this can be a mandatory or voluntary process and can take various forms from budget alignment or a fully integrated budget between two or more sectors. They have sometimes been accompanied by legislation, regulatory instruments and legal agreements between sectors.

- Delegated Funding: Suggests the allocation of funds from one or more sources to an independent statutory organization such as a Foundation; this implies a transfer of power and criteria to prioritize government programs. The funds come from various tariffs such as: excise duty on large and profitable companies; rate on foreign exchange transactions; diaspora bonds; taxed on financial transactions; voluntary mobile phone solidarity contribution; tobacco, alcohol and unhealthy foods.

- Independent public fund: It allows to adopt an innovative approach without having to face bureaucratic obstacles and act beyond its scope outside the health sector to address social determinants in health. In this option, careful design of legislation or regulation is essential to ensure a lot of funding for the entire population.

- Tax incentives: This financing mechanism may be particularly relevant to promoting better health in small and medium-sized enterprises, for example by allowing some corporate taxes to deduct the costs of investing in promotion plans workplace health.

- Resources in kind: This could include agreements on staff affiliation between sectors, sharing knowledge or equipment, as well as providing space to host a project or activity.

Political and legislative contexts can influence the choice and viability of each or all of these specific sources of funding, as they reflect power relations within and outside government; as well as ideological values and perspectives of stakeholders. In this sense, in order to secure the funds it is necessary to highlight three premises: First, implementing legislative mechanisms as a way to promote complementarity and financial sustainability; secondly, promote opportunities for cross-sectoral action; this is critical with the aim of changing the culture and discourse around health criteria 
in the offices of a wide range of government authorities that have not previously considered health as part of the agenda. Finally, create a range of potential funding sources beyond government health budgets. A prerequisite for collaboration with organizations outside the health sector is that organizations are willing to devote their resources and; to do so, incentives and co-benefits are necessary in order to maximize social and individual well-being.

\section{Monitoring and Evaluation}

Monitoring and evaluation of health in all policies poses practical, theoretical and methodological challenges. As we have already described, the model operates in complex and dynamic systems involving a range of sectors and disciplines, starting from multiple knowledge bases. It occurs within changing political and operational contexts and involves many diverse actors, - some convergent, others divergent, with objectives, values and reasons to support - or not - a policy proposal; this is because causal chains are often nonlinear and involve negotiation and feedback $[67,68]$.

The development of a monitoring and evaluation framework articulates the causal chains that underpin the resulting policy in the short, intermediate and long term; as such lays the foundation for explaining the paths through which processes, impacts and health outcomes can be realized, even if projects cannot continue long enough to see these impacts.

The starting point is the development of a logical model that can characterize the activities and different elements that work and interact, to prioritize those actions that have the greatest impact and can strengthen coherence and efficiency between sectors, in particular, in the context of policy frameworks addressing social determinants of health and identifying the effectiveness of government, socioeconomic and environmental interventions; its possible side effects and comparison with other alternative uses of available resources [69].

Consequently, a clear articulation of the logic that underpins health in all policies is necessary to shape the System. It should be about establishing causality by the 'weight of evidence' that supports logically coherent strings of relationships that arise through contrast and comparison of findings of many existing and relevant forms of evidence. This technique would allow us to make a series of assumptions - behind political interventions - about the implementation of the model, which can link the immediate results of the long-term health initiative and the welfare outcomes considered more important by stakeholders.

Therefore, the system will examine: 1) the fundamentals of the policy established, including the definition of problems, scope and actors through a participatory and iterative process; 2) long-term policy development that circumscribes options, relative benefits and trade-offs for different stakeholders; 3) policy implementation on their scope, implementation process, community-level probity and social justice-related significance; 4) changes in health for the environment or social development and range of adoption, use or practices leading to health and; 5) improvements in health indicators prospectively and anti-risk measures of the population, increased well-being, changes in health-related social norms and that are part of the reality of the policy $[22,70,71]$.

In line with the described, the Pan American Health Organization has pointed to a Roadmap [48] and four groups of indicators that involve a judgment on the degree of progress of the requirements or key elements [72].

- Key aspects of the implementation of the plan and the generation of favorable conditions, with the aim of: a) to raise awareness of the health and equity impacts of public policy and feedback to the sectors involved that may lead to the development of interactions; b) the exchange of formal information in regional and local bodies that provide the above and lead the process from the available evidence; c) accountability for the involvement of citizens and civil society, to facilitate work with other sectors and to carry out social control of public policies and; d) generate profiles of social determinants that identify the sectors that need to be concur to address issues related to inequity and help establish the precise priority actions.

- Characterize initiatives underway in four priority areas for success: a) reducing social inequities and determining the approach used on equitable solutions; b) the inclusion, in the health sector, of the needs and priorities of the other sectors; c) inclusion of health as an objective or goal in other sectoral policies, identifying levels of implementation and levels of health influence and impact in all policies in the health sector and other sectors; d) quality of health interactions in all policies to deepen work with other sectors, beyond the usual collaborations.

- Ensure follow-up so that collaboration between public and private partners increases the efficiency and accuracy of programmes; and.

- Develop knowledge and skills for the team that seeks to understand the extent to which government organizations and the community address the need for knowledge training and development in various fields.

To conclude this heading, health in all policies has multiple outcomes, ranging from creating a more collaborative and health-oriented organizational culture, 
promoting healthy public policies and decision-making processes that are related to policy changes that aim to improve the equity and health of the population. In these circumstances, it is legitimate and practical to use a number of indicators of progress at different levels. Our proposal uses five components of the model: 1) political potential; 2) policy development; 3 ) the uniformity of the process of the extension and nature of policy implementation across the target population, particularly in vulnerable communities; 4) the conditions and practices resulting from the implementation of policies that are conducive to the health of the population and; 5) mitigation or elimination of risk, improvement of health or well-being of the population.

\section{Some Reflections as Conclusion}

In general, the model is feasible in a variety of fields and countries at all stages of development and at all income levels, including in resource-constrained settings. In this sense, policy makers should be prepared to consider adapting to levels of social and economic development, the degree of political priority according to the scale of the problem, the feasibility of meaningful engagement and possible health consequences on communities, equity and the context of health systems.

While it is important to consider the role of specific political, cultural and geographical contexts in planning the implementation of the model, this requires thinking about a long-term strategy and sense of time. However, time could be shortened if trained personnel are employed, the introduction of horizontal structures and governance strategies that promote inter-agency partnerships, and accountability among governments in the pursuit of shared social objectives.

We recognize that these changes will not be easy to implement and solutions go beyond the limits of current public health. One of the main challenges in all these initiatives is sustainability; this includes political sustainability to maintain the will of the highest authority at each level of government, conceptual sustainability to systematically preserve the model in the context of conflicts of interest aggravated by strictly sectoral judgments within public bodies, and financial sustainability to maintain structures and processes influenced by economic uncertainty.

In this knowledge, interventions can be promoted as a means of controlling care costs by mitigating health-related social problems; in addition, cross-sectoral action is driven as a way to address overlap and redundancy in times of fiscal restraint. Similarly, financing practices, such as integrated budgets and joint accounting, are critical to addressing the economic considerations of policies that arise in the jurisdictions in which those are applied.

However, adopting the model would strengthen the public system's ability to respond to previous threats and the benefits of an integrated system overcome any of these challenges, regardless of implementation difficulties arising in its development, so that healthy communities exist.

Aware that such an evolution, to be effective and efficient, involves efforts in unison from the base of the system to the highest levels of political decision-making; we think it appropriate to mention your pre-requirements: (1) Political and functional decentralization as a principle of administrative organization; (2) political and executive leadership that achieves appropriate horizontal linkage in the sectors, as well as the vertical linkage of levels within the organization; (3) effective and efficient citizen participation that achieves the equitable distribution of power, money and resources in the formulation, implementation and monitoring of redistributive policies; (4) the integration of health goals with social objectives in general, addressing social determinants of health, ensuring greater policy coherence and achieving 'win-win' goals; (5) partnershipbased participatory planning as a result of the use of a consensual paradigm between society and governments to mitigate health and well-being inequities; and 6) constant accompaniment, monitoring and evaluation of the context so that the initiative can adapt to changing political/economic/ social circumstances and show the success achieved.

\section{References}

1. World Health Organization (2000) The world health report 2000: health systems: improving performance. Geneva, Switzerland.

2. Organización Panamericana de la Salud, Organización Mundial de la Salud (2007) Renovación de la atención primaria de salud en las Américas, Washington.

3. WHO Regional Office for Europe (2008) The Tallinn Charter: health systems for health and wealth. Copenhage, Denmark: WHO.

4. Conferencia Internacional sobre Atención Primaria (1978) Salud para todos en el año 2000. Alma Ata, Kazajistán: OMS.

5. (1986) Carta de Ottawa para la Promocion de la Salud. Primera Conferencia Internacional sobre Promocion de la Salud. OMS, Ottawa, pp: 1-4.

6. Pan American Health Organization, World Health Organization (2014) Strategy for universal access to health and universal health coverage. 53rd Directing 
Council. 66th Session of the Regional Committee of WHO for the Americas. Resolución CD53/R5, Rev. 2-Annex A. Washington, DC: PAHO/WHO.

7. Organización Panamericana de la Salud (2017) Agenda de salud sostenible para las Américas 2018-2030: un llamado a la acción para la salud y el bienestar en la Región. 29a Conferencia Sanitaria Panamericana. 69a Sesión del Comité Regional de la OMS para las Américas. CSP29/6, Rev. 3. Washington, DC: OPS.

8. (2010) Declaración de Adelaida sobre la Salud en Todas las Políticas: Hacia una gobernanza compartida en pro de la salud y el bienestar. OMS, Gobierno de Australia Meridional, Adelaida, pp: 1-4.

9. World Health Organization (2013) The Helsinki Statement on Health in All Policies. Geneva, Switzerland: WHO.

10. Ministerio de Sanidad y Asistencia Social/Organización Panamericana de la Salud (1991) Desarrollo y Fortalecimiento de los Sistemas Locales de Salud en Venezuela. Experiencias I. Caracas, Venezuela: MSAS/ OPS/OMS.

11. Ministerio de Sanidad y Asistencia Social/Organización Panamericana de la Salud (1992) Desarrollo y Fortalecimiento de los Sistemas Locales de Salud en Venezuela. Experiencias II. Caracas, Venezuela: MSAS/ OPS/OMS.

12. Ministerio de Sanidad y Asistencia Social/Organización Panamericana de la Salud (1993) Desarrollo y Fortalecimiento de los Sistemas Locales de Salud en Venezuela. Experiencias III. Caracas, Venezuela: MSAS/ OPS/OMS.

13. Ministerio de Sanidad y Asistencia Social/Organización Panamericana de la Salud (1994) Desarrollo y Fortalecimiento de los Sistemas Locales de Salud en Venezuela. Experiencias IV. Caracas, Venezuela: MSAS/ OPS/OMS.

14. Ministerio de Sanidad y Asistencia Social/Organización Panamericana de la Salud (1996) Proyecto Municipios hacia la Salud. Experiencia Venezolana. Tomo I, Caracas, Venezuela: MSAS/OPS/RVMHS.

15. Ministerio de Sanidad y Asistencia Social/Organización Panamericana de la Salud (1999) Proyecto Municipios hacia la Salud. Experiencia Venezolana. Tomo II, Caracas, Venezuela: MSAS/OPS/RVMHS.

16. World Health Organization (2013) Demonstrating a health in all policies analytic framework for learning from experiences: based on literature reviews from Africa, South-East Asia and the Western Pacific. Geneva, Switzerland: WHO.

17. Kickbusch I, Behrend T (2013) Implementing a Health 2020 vision: governance for health in the 21st century. Making it happen. Copenhage, Denmark: WHO/EUR.

18. De Leeuw E, Green G, Spanswick L, Palmer N (2015) Policymaking in European healthy cities. Health Promot Int 30(S1): i18-i31.

19. Alleyne G (2015) Salud en todas las políticas: el control y la prevención de enfermedades crónicas no transmisibles. Salud pública de México 57(3): 284-287.

20. Mandl Stangl J (2018) Nuevas Prácticas y Significados en Politicas Públicas Saludables: Un Modelo de Gestión, Editorial Académica Española, Beau Bassin Mauritius $5(1)$.

21. Kickbusch I (2008) Healthy Societies: addressing $21^{\text {st }}$ century health challenges. Department of the Premier and Cabinet Adelaide, State of South Australia.

22. Rudolph L, Caplan J, Ben-Moshe K, Dillon L (2013) Health in All Policies: A Guide for State and Local Governments, American Public Health Association and Public Health Institute, Washington, DC.

23. Jackson SF, Birn AE, Fawcett SB, Poland B, Schultz JA (2013) Synergy for health equity: integrating health promotion and social determinants of health approaches in and beyond the Americas. Rev Panam Salud Pública 34(6): 473-480.

24. Monsiváis Carrillo A (2014) La deliberación como mecanismo de control democrático: precisiones analíticas y cuestiones emergentes. Revista mexicana de sociología 76(3): 471-499.

25. Pan American Health Organization (2017) Health in All Policies: from the local to the global. Washington, DC: PAHO.

26. World Health Organization (2015) Health in all policies: training manual. Geneva, Switzerland: WHO.

27. Natera Peral A (2005) La gobernanza como modo emergente de gobierno y gestión pública. GAPP 33-34: $53-65$.

28. Zurbriggen C (2011) Gobernanza: una mirada desde América Latina. Perfiles latinoamericanos 19(38): 3964.

29. Buss PM (2014) Gobernanza global para la 
salud. Cadernos de Saúde Pública. 30(4): 681-683.

30. Kickbusch I, Gleicher D (2012) Governance for health in the $21^{\text {st }}$ century. Copenhage, Denmark: WHO/EUR.

31. Mandl Stangl J (2017) Gobernanza de políticas públicas saludables en los ámbitos locales: una propuesta para el debate. Cuadernos del CENDES 96: 65-86.

32. Greer S, Maresso A (2012) Intersectoral problem solving by Interdepartmental Units and Committees. Eurohealth OBSERVER 18(4): 11-14.

33. McQueen D, Wismar $M$, Lin V, Jones CM, Davies $M$ (2012) Intersectoral governance for Health in All Policies. Structures, actions and experience. Copenhage, Denmark: WHO/EUR on behalf of the European Observatory on Health Systems and Policies.

34. Bert F, Scaioli G, Gualano MR, Siliquini R (2015) How Can We Bring Public Health in All Policies? Strategies for Healthy Societies. Journal of Public Health Research 4(1): 43-46.

35. World Health Organization (2018) Key learning on Health in All Policies implementation from around the world - Information Brochure. Geneva, Switzerland: WHO/EUR.

36. Kickbusch I, Lin V (2017) Progressing the Sustainable Development Goals through Health in All Policies: Case studies from around the world, Adelaide: Government of South Australia.

37. Cunill Grau N (2014) La intersectorialidad en las nuevas políticas sociales: Un acercamiento analítico-conceptual. Gestión y política pública 23(1): 5-46.

38. Ndumbe Eyoh S, Moffatt H (2013) Intersectoral action for health equity: a rapid systematic review. BMC Public Health 13: 1056.

39. Organización Panamericana de la Salud (2015) Intersectorialidad y equidad en salud en América Latina: una aproximación analítica. Washington, DC: OPS.

40. Rantala R, Bortz M, Armada F (2014) Intersectoral action: local governments promoting health. Health Promot Int. 29 (suppl_1): i92-i102.

41. Eriksson M (2011) Social capital and health-Implications for health promotion. Global Health Action 4(1): 5611.

42. Wallerstein N (1992) Powerlessness, empowerment, and health: implications for health promotion programs. Am J Health Promot 6(3): 197-205.
43. Sapag JC, Kawachi I (2007) Capital social y promocion de la salud en América Latina. Rev Saude Publica 41(1): 139-149.

44. Bossert TJ (1990) Can they get along without us? Sustainability of donor - supported health projects in Central America and Africa. Soc Sci Med 30(9): 10151023.

45. Thompson B, Winner C (1999) Durability of community intervention programs: definitions, empirical studies, and strategic planning. In Bracht N, ed., Health promotion at the community level: new advances. $2^{\text {nd }}$ (Edn.), Newbury Park, USA: SAGE pp: 137-154.

46. Freiler A, Muntaner C, Shankardass K, Mah CL, Molnar A, et al. (2013) Glossary for the implementation of Health in All Policies (HiAP). Journal of Epidemiology and Community Health 67(12): 1068-1072.

47. Clavier C (2016) Implementing health in all policies-time and ideas matter too! Comment on "Understanding the role of public administration in implementing action on the social determinants of health and health inequities. Int J Health Policy Manag, 5(10): 609-610.

48. Organización Panamericana de la Salud (2016) Hoja de Ruta para el Plan de Acción sobre la Salud en Todas las Políticas. Washington, D.C., OPS.

49. Hoeijmakers M, De Leeuw E, Kenis E, De Vries NK (2007) Local health policy development processes in the Netherlands: an expanded toolbox for health promotion. Health Promotion International 22(2): 112-121.

50. Mauti J, Gautier L, De Neve JW, Beiersmann C, Tosun J, et al. (2019) Kenya's Health in All Policies strategy: a policy analysis using Kingdon's multiple streams. Health Research Policy and Systems 17: 15.

51. Republica del Perú/Ministerio de Salud (2015) Metodología para el análisis de situación de salud local. Documento Técnico. Lima, Perú: MINSA.

52. Commission to Build a Healthier America (2011) Health Impact Assessment: A Tool for Promoting Health in All Policies. Washington, DC: Robert Wood Johnson Foundation.

53. Organización Panamericana de la Salud (2013) Salud en todas las políticas en las Américas. Resumen de las experiencias de las Américas. Helsinki, Finlandia, OPS.

54. Institute of Medicine (2011) For the Public's Health: Revitalizing Law and Policy to Meet New Challenges. Washington, DC: The National Academies Press. 
55. Organización Panamericana de la Salud (2002) La Salud Pública en las Américas: Nuevos Conceptos, Análisis del Desempeño y Bases para la Acción. Publicación Científica y Técnica No. 589, Washington DC: OPS.

56. McKee M, Stuckler D, Dorner T, Zeegers Paget D (2016) The Vienna Declaration. Eur J Public Health 26(6): 897898.

57. Novena Conferencia Mundial de Promoción de la Salud (2016) La promoción de la salud en los Objetivos de Desarrollo Sostenible, Shanghai, China, OMS.

58. Johnson R, Wooten H (2015) From Start to Finish: How to Permanently Improve Government through Health in All Policies. Oakland, CA: ChangeLab Solutions.

59. Polsky C, Stagg K, Gakh M, Bozlak CT (2015) The Health in All Policies (HiAP) Approach and the Law: Preliminary Lessons from California and Chicago. Journal of law, medicine \& ethics 43(s1): 52-55.

60. Bonvecchio A, Becerril Montekio V, Carriedo Lutzenkirchen Á, Landaeta Jiménez M (2011) Sistema de salud de Venezuela. Salud Pública de México 53(S2): s275-s286.

61. Cetrángolo O (2015) La reasignación de recursos públicos para equidad en salud. In Ferrelli, RM., ed., Equidad en salud desde un enfoque de determinantes sociales. Contribuciones del encuentro regional "La toma de decisiones para la equidad en salud", Documento de Trabajo no 39, EUROsociAL, Madrid, España, pp: 49-66.

62. Frenk J (2015) Señalando el camino hacia la cobertura universal de salud: un llamado a la acción. MEDICC Rev 17 (S): 62-72.

63. National Academies of Sciences, Engineering, and Medicine (2017) Building sustainable financing structures for population health: Insights from nonhealth sectors. Washington, DC: The National Academies Press.

64. Pinto AD, Molnar A, Shankardass K, O'Campo PJ, Bayoumi AM (2015) Economic considerations and health in all policies initiatives: evidence from interviews with key informants in Sweden, Quebec and South Australia. BMC Public Health 171.

65. Watabe A, Wongwatanakul W, Thamarangsi T, Prakongsai P, Yuasa M (2017) Analysis of health promotion and prevention financing mechanisms in Thailand. Health Promotion International 32(4): 702-710.

66. McDaid D, Park A-L (2016) Evidence on financing and budgeting mechanisms to support intersectoral actions between health, education, social welfare and labour sectors. Health Evidence Network (HEN) synthesis report 48 Copenhage Denmark, pp: 1-49.

67. Bauman AE, King L, Nutbeam D (2014) Rethinking the evaluation and measurement of health in all policies. Health Promotion International 29(suppl_1): i143-i151.

68. Baum F, Lawless A, Delany T, Macdougall C, Williams C, (2014) Evaluation of Health in All Policies: concept, theory and application. Health Promotion International 29(suppl_1): i130-i142.

69. Pega F, Valentine NB, Rasanathan K, Hosseinpoor AR, Torgersen TP, et al. (2017) The need to monitor actions on the social determinants of health. Bulletin of the World Health Organization 95(11): 784-787.

70. Lawless A, Baum F, Delany Crowe T, MacDougall C, Williams C, et al. (2017) Developing a framework for a program theory-based approach to evaluating policy processes and outcomes: Health in All Policies in South Australia. Int J Health Policy Manag 7(6): 510-521.

71. Baum F, Delany Crowe T, MacDougall C, van Eyk H, Lawless A, et al. (2019) To what extent can the activities of the South Australian Health in All Policies initiative be linked to population health outcomes using a program theory-based evaluation? BMC Public Health 19(1): 88.

72. Organización Panamericana de la Salud (2017) Validación de indicadores para la implementación del Plan de Acción sobre la Salud en Todas las Políticas: propuesta de aplicación a nivel nacional. Washington, D.C.: OPS. 